\title{
Evidence from the oestrous cycle for male-induced ovulation in Bettongia penicillata (Marsupialia)
}

\author{
M. J. Smith \\ Evolutionary Biology Unit, South Australian Museum, North Terrace, Adelaide SA 5000, Australia
}

\begin{abstract}
Summary. Female brush-tailed bettongs (Bettongia penicillata) housed in a breeding group of one male and one to three females had an average gestation period of 21.2 days $(n=58)$ and parturition was followed within $24 \mathrm{~h}$ by oestrus and mating. If a young was not born as a result of the mating, oestrus recurred after about 21.7 days $(n=12)$. From removal of pouch young to birth was $17 \cdot 5$ days, on average $(n=85)$, in females that had mated post partum, but most females that were isolated from a male before parturition returned to oestrus about 6.6 days after simultaneous removal of pouch young and return to the male $(n=9)$. Females housed in female-only groups appeared not to come into oestrus or to do so irregularly. These females, when returned to the male, usually came into oestrus within 10 days. These data provide evidence that, in most females of $B$. penicillata, ovulation does not occur in the absence of a male and that previously isolated females return to oestrus within 10 days of return to the male.
\end{abstract}

Keywords: gestation period; marsupial reproduction; brush-tailed bettong

\section{Introduction}

The reproduction pattern has been determined, at least broadly, for many kangaroos, wallabies and rat-kangaroos of the marsupial superfamily Macropodoidea; two species, Macropus eugenii and $M$. rufogriseus (Macropodidae), have been investigated in great detail (reviewed by TyndaleBiscoe \& Renfree, 1987). All published studies of reproduction of macropodoid species have found them to ovulate spontaneously, to be polyoestrous, and, with the exception perhaps of Hypsiprymnodon moschatus, to be monovular. Embryonic diapause is a common feature of reproduction in macropodoids and in only one species, $M$. fuliginosus, has no form of embryonic diapause been found (Tyndale-Biscoe \& Renfree, 1987). In most species, ovulation occurs within 3 days of parturition and, provided that the neonate successfully establishes lactation, the newly formed corpus luteum becomes quiescent and the embryo enters diapause as a unilaminar blastocyst consisting of about 80 apparently undifferentiated cells (Smith, 1981).

All extant species of the family Potoroidae (the rat-kangaroos) are believed to have post partum oestrus and embryonic diapause for most of the duration of pouch suckling (Tyndale-Biscoe, 1984). The length of the oestrous cycle ranges from an average of 42 days in Potorous tridactylus to 22-23 days in three species of Bettongia; and, in all species, gestation length is 1-4 days shorter, 38 days on average in $P$. tridactylus and 21 days in Bettongia species. The duration of delayed gestation, i.e. the interval between removal of the pouch young and birth of a neonate resulting from the diapause embryo, is shorter again, 29 days in $P$. tridactylus and 18 days in $B$. lesueur and B. gaimardi.

Some data on reproduction in B. penicillata are available (Parker 1977; Smith 1989). The present paper describes studies on the duration of gestation, the oestrous cycle and related reproductive characteristics in this species. 


\section{Materials and Methods}

\section{Animals}

A colony of approximately $150 \mathrm{~B}$. penicillata is maintained at the Evolutionary Biology Unit of the South Australian Museum. This colony is derived from five females and several males received in 1982 and 1984 from stock formerly maintained by the South Australian National Parks and Wildlife Service, derived from animals of the subspecies B. penicillata ogilbyi from Western Australia (Delroy et al., 1986). The data presented here were obtained between January 1986 and 31 December, 1990. There is no sexual dimorphism in this species and adult males and females weigh 900-1300 g (M. J. Smith, unpublished).

The animals were held in $4-8 \mathrm{~m}^{2}$ pens. Breeding pens, occupied by one male and $1-3$ females, were either outdoors in aviaries or in a masonry shed with natural light and natural temperature. Holding pens occupied by only females were located in a lined, galvanized iron shed, with natural light, supplemented between $07: 00 \mathrm{~h}$ and 17:00 $\mathrm{h}$ by fluorescent lighting, and at temperature $15^{\circ}-30^{\circ} \mathrm{C}$; at no time was a male older than 4 months housed in this shed. Females in holding pens were therefore totally isolated from the pheromonal as well as the physical influence of adult males.

The animals' diet consisted of apples, bananas, bread, parrot seed mix, dry dog food, hard-boiled eggs and pellet-form kangaroo rations (Milling Industries Ltd, South Australia). Water was provided ad libitum.

The animals of this colony are amenable to frequent handling. However, for examination of the pouch or taking a vaginal smear, the animal was restrained in a light cloth bag. Females were examined daily between 09:00 $\mathrm{h}$ and $11: 00 \mathrm{~h}$ for signs of birth or mating; occasionally animals were examined more frequently.

\section{Vaginal smears}

A moistened glass speculum was inserted into the urogenital sinus and, by means of a moistened wire loop inserted through this speculum, the contents of the upper region of the urogenital sinus were sampled. This sample was microscopically examined immediately, under phase contrast at $\times 100$. The abundance of nucleated, partly cornified and cornified epithelial cells and of polymorphonuclear leucocytes was graded from 1 to 5 , for each cell type separately, 5 indicating a very high density. The first day on which cornified epithelial cells were given a score of 5 was considered to be the day on which oestrus had occurred (after Sharman \& Calaby (1964) for Macropus rufus). Mating was confirmed by observation of semen around the vulva or spermatozoa in the vaginal smear.

\section{Duration of gestation}

Duration of gestation is defined as the interval between mating and birth when no young occupy the pouch. Females were examined daily until mating was detected. Of the 58 females which subsequently gave birth, 45 were removed after mating from the breeding pen to holding pen until at least 19 days after mating. Thirteen females remained with the male after mating and until parturition. Females were examined for the presence of a neonate in the pouch daily from the nineteenth day after mating.

\section{Duration of oestrous cycle}

The oestrous cycle was defined as the interval between two successive matings when a neonate was not known to have been produced as a result of the first mating and when the female was not separated from the male for more than 19 days after the first mating. It is recognized that some oestrous cycles measured in this way could, in fact, have been a gestation and post partum mating in circumstances where the neonate did not reach the pouch. The oestrous cycle was measured on 12 occasions.

\section{Parturition to post partum oestrus}

Parturition to post partum oestrus was measured as the inverval between the finding of a neonate in the pouch and the confirmation of mating in females that had been with the male for at least 2 days before parturition. This interval was observed on 80 occasions.

\section{Delayed gestation period}

Delayed gestation period was taken as the interval between the permanent removal from the pouch of a 3-80-day-old young and the birth of a neonate derived from a diapause embryo. This interval was measured on 85 occasions. 


\section{Delayed oestrous cycle}

Delayed oestrous cycle was measured in two ways. (i) In ten females that had been isolated from males during pregnancy, parturition and lactation until the day of removal of pouch young, the delayed oestrous cycle was measured as the interval between removal of pouch young and oestrus when the female was returned to the male at the time of removal of pouch young. The occurrence of oestrus was determined by daily vaginal smear from the day after removal of pouch young until oestrus. (ii) In six females that had mated post partum but had failed to give birth after removal of pouch young, the delayed oestrous cycle was measured as the interval between removal of pouch young and oestrus when the female was with the male continuously from no later than the time of removal of pouch young.

\section{Time to oestrus after return to the male after a period of isolation}

Twenty females were isolated from males during an infertile cycle after a known mating. At either 8,9 or 10 days after oestrus was expected (on the premise for conventional macropodids that the oestrous cycle length is of approximately the same duration as the interval between mating and post partum mating), the female was returned to the male and vaginal smears were taken daily until oestrus was detected.

\section{Oestrus in females isolated from males}

Ten nonlactating females that had been isolated from males for at least 30 days were isolated from males for a further 25 days during which vaginal smears were taken daily and examined for indication of oestrus. The potential fertility of each of these females was assessed by returning them to the male on the 26th day and continuing daily vaginal smears until oestrus.

\section{Results}

\section{Duration of gestation}

In 45 females isolated from the male as soon as mating had been detected, the mean gestation period was 21.2 days (range 20-23 days, SEM 0.09 days); in 13 females that remained with the male the mean gestation period was $21 \cdot 2$ days (range 20-22 days, SEM $0 \cdot 2$ days). The modal duration of gestation was 21 days (Table 1). The only gestation longer than 22 days occurred in a female that was removed from the male as soon as mating was detected.

Table 1. Duration of the gestation period and of the oestrous cycle in females of Bettongia penicillata examined once a day

\begin{tabular}{|c|c|c|c|c|}
\hline & \multicolumn{2}{|c|}{ Gestation } & \multicolumn{2}{|c|}{ Oestrous cycle } \\
\hline & $\begin{array}{l}\text { Duration } \\
\text { (days) }\end{array}$ & $\begin{array}{l}\text { Number of } \\
\text { times observed }\end{array}$ & $\begin{array}{l}\text { Length } \\
\text { (days) }\end{array}$ & $\begin{array}{l}\text { Number of } \\
\text { times observed }\end{array}$ \\
\hline & 20 & 7 & 20 & 1 \\
\hline & 21 & 35 & $2 \mathrm{I}$ & 2 \\
\hline & 22 & 15 & 22 & 8 \\
\hline & 23 & 1 & 23 & 1 \\
\hline Total observed & - & 58 & - & 12 \\
\hline Mean \pm SEM (days) & $21 \cdot 2 \pm 0.09$ & - & $21.7 \pm 0.2$ & - \\
\hline
\end{tabular}

\section{Duration of the oestrous cycle}

The oestrous cycle (Table 1) ranged from 20 to 23 days (as did the gestation period), but the mean oestrous cycle was 0.5 days longer than the mean duration of gestation. Seven females that remained with the male after the first mating had an average oestrous cycle of 21.9 days (SEM 0.9 days) and five females that were separated from the male for up to 19 days after the first mating had an average oestrous cycle of 21.6 days (SEM 0.3 days). 


\section{Parturition to post partum oestrus}

On a total of 61 occasions, in females checked once a day, post partum mating had already occurred when the neonate was found, i.e. birth and mating occurred within $24 \mathrm{~h}$. On 15 occasions, at the time of discovery of the neonate, the male was attempting to mount the female, and on one other occasion, mating was observed $30 \mathrm{~min}$ later. A female that gave birth between 09:00 $\mathrm{h}$ and 14:30 $\mathrm{h}$ had mated when next examined at 09:00 $\mathrm{h}$ the following day. Another female that was observed giving birth at 10:20 h had already mated when examined at 14:15 h on the same day.

\section{Delayed gestation period}

The interval between removal of pouch young and the observation of a neonate ranged from 15 days 22 hours to 19 days 21 hours (mean 17.5 days, SEM 0.09 days, $n=85$ ). On three occasions birth was observed and so the interval between removal of pouch young and birth could be determined precisely. These intervals were 16 days $23 \mathrm{~h} 15 \mathrm{~min}, 16$ days $22 \mathrm{~h} 20 \mathrm{~min}$ and 16 days $23 \mathrm{~h} 0 \mathrm{~min}$. On another occasion the neonate was found in the pouch but not yet attached to the teat and the interval was 16 days $21 \mathrm{~h}$.

\section{Delayed oestrous cycle}

The ten females that had been isolated from males during pregnancy, parturition and lactation until the time of removal of pouch young all returned to oestrus after simultaneous removal of pouch young and return to the male (Fig. 1). Nine of the ten returned to oestrus and mated in less than 17.5 days (the mean interval between removal of pouch young and parturition). The mean interval between removal of pouch young and oestrus in those nine females was 6.6 days (SEM 0.3 days). One of the ten returned to oestrus 18 days after removal of pouch young, at the time oestrus would have been expected to occur in a female that had been mated post partum and had given birth after removal of pouch young. Six of the ten females produced a neonate 20, 21 or 22 days after mating at oestrus that was detected after removal of pouch young and two others returned to oestrus 21 and 23 days later, respectively.

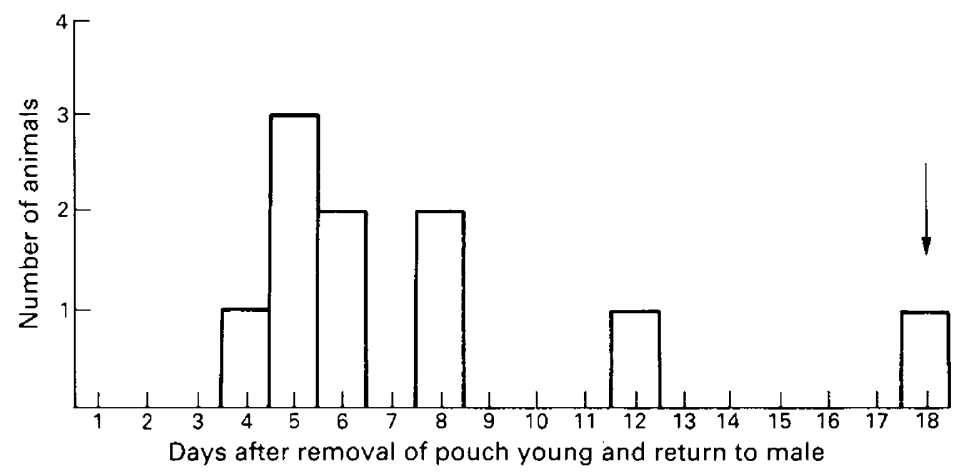

Fig. 1. Time of return to oestrus after simultaneous removal of pouch young and return to the male in female Bettongia penicillata that had been isolated from males since the mating at which the pouch young was conceived. Arrow indicates average time of return to oestrus after removal of pouch young in females that had mated post partum and undergone an infertile cycle. 
In the six females that had mated post partum the interval between removal of pouch young and the detection of mating ranged from 17 days $22 \mathrm{~h}$ to 19 days $21 \mathrm{~h}$ (mean 18.6 days, SEM 0.3 days).

\section{Time to oestrus after return to the male after a period of isolation}

Eighteen of the 20 females, after being returned to the male, came into oestrus within 25 days of the expected oestrus at which the female was isolated from the male, i.e. the oestrus that would have occurred if the brush-tailed bettong had a regular 22 day oestrous cycle. Sixteen of these cycles occurred earlier than would have been expected from a regular 22 day cycle (Fig. 2). Of the females put with the male on day 8 of the expected cycle, five came into oestrus an average of 4.0 days later, i.e. an average of 10.0 days before the next expected oestrus; of those put with the male on day 9 , six came into oestrus an average of 5.7 days later, i.e. an average of $7 \cdot 3$ days before the next expected oestrus; and of those put with the male on day 10 , five came into oestrus an average of 5.0 days later, i.e. an average of $7 \cdot 0$ days before the next expected oestrus. One day- 8 and one day- 10 female came into oestrus 2 and 3 days, respectively, after the expected oestrus (Fig. 2). Two females were not detected to have returned to oestrus within 25 days of return to the male. For each of those the next detected reproductive event was parturition at 68 and 72 days, respectively, after being put with the male.

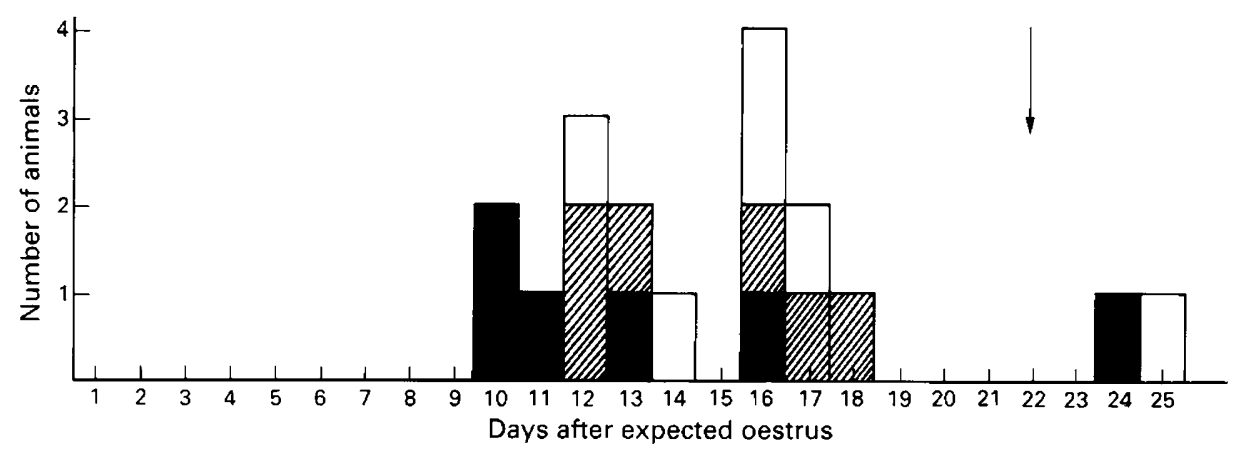

Fig. 2. Time of return to oestrus in female Bettongia penicillata that had been isolated from males at the previous expected oestrus. Females were returned to the male at day 8 (filled columns), day 9 (crosshatched columns) or day 10 (open columns). Arrow indicates expected day of oestrus if $B$. penicillata were to have regular 22 day oestrous cycles.

\section{Oestrus in females isolated from males}

In five of the ten females kept in isolation from males, there was no indication from vaginal smears that oestrus had occurred. However, one of these was not detected to have returned to oestrus within 25 days of return to the male. The other four returned to oestrus 5, 5, 6 and 6 days, respectively, after return to the male.

One female had continuous oestrus-like smears for the whole 25 days in isolation and for 2 days after return to the male; this animal then showed very few cells in the smear for 2 days followed by oestrus and mating on the fifth day. A neonate resulted from this mating.

One female had oestrus-like smears on days 12-14, 18-20 and 25 during isolation and came into oestrus and mated on day 3 after return to the male, this being 3 days after the previous onset of oestrus-like smears.

The three remaining females had one period of oestrus-like smears, starting on day 2, 16 or 11 , respectively, during isolation. After return to the male these females returned to oestrus and mated 7 days after return to the male ( 29 days after oestrus-like smears), 10 days after return to the male 
(20 days after oestrus-like smears) or 1 day after return to the male (15 days after oestrus-like smears), respectively.

\section{Discussion}

When female brush-tailed bettongs have continuous access to males, the pattern of reproduction conforms with that of most macropodoids. This is group 3 pattern of marsupial reproduction (Tyndale-Biscoe \& Renfree, 1987), characterized by an extended luteal phase, gestation period almost the same length as the oestrous cycle and post partum oestrus. Within this group two other bettong species, B. gaimardi and $B$. lesueur, have been shown to have the shortest oestrous cycle and gestation period, of 22 and 21 days, respectively (Rose, 1987; Tyndale-Biscoe, 1968). B. penicillata closely resembles these two congeners in oestrous cycle length and gestation period. Similarly, the interval between removal of pouch young and birth is approximately 18 days in all three species. Group 3 species are believed to ovulate spontaneously and to have a regular oestrous cycle within the breeding season, irrespective of the presence of males.

However, the results presented here indicate that when $B$. penicillata females are isolated from males only a small proportion ovulate spontaneously. This was most clearly shown in the different time interval between removal of pouch young and oestrus when females had either been allowed to mate post partum or had been isolated from males post partum, the interval being approximately 18.5 days in the females mated post partum but on average 6.6 days in nine of ten females isolated from males post partum. Only one female isolated from males post partum returned to oestrus 18 days after removal of pouch young. Oestrus in the former nine females indicated that, at about 6.6 days after removal of pouch young, there was no active corpus luteum on either ovary. This situation could have arisen because (i) a corpus luteum formed at post partum ovulation degenerated before day 6 after removal of pouch young, this rapid degeneration occurring only in nonmated females or (ii) a corpus luteum had not been formed post partum and that 6.6 days was the average time required for development of a follicle to maturity, i.e. the follicular phase of the oestrous cycle.

Additional evidence for a lack of spontaneous ovulation comes from the ability of most females to return to oestrus before the expected day after being returned to the male in what would have been mid-cycle (if they were to have been undergoing a regular cycle) following an expected oestrus at which they were isolated from the male. Moreover, when nonpregnant nonlactating females were kept isolated from males, many of them did not show any evidence of oestrus in the daily vaginal smear. After being returned to the male nine of these ten females came into oestrus within 10 days.

Progesterone concentrations in the blood of females after removal of pouch young provide further evidence that most $B$. penicillata females require the presence of a male for ovulation to occur. Most females that were allowed to mate post partum with either an intact or a vasectomized male showed a biphasic rise in circulating progesterone concentration after removal of pouch young, the early peak rising to an average of $1206 \mathrm{pg} \mathrm{ml}^{-1}$ in plasma $(n=16)$ and the later peak to $>800 \mathrm{pg} \mathrm{ml}^{-1}$. In contrast, on 12 of 15 occasions, females that were isolated from males post partum had low $\left(<100 \mathrm{pg} \mathrm{m}^{-1}\right)$ and unchanging plasma progesterone concentrations after removal of pouch young (Hinds \& Smith, 1991).

The possibility that the presence of a conspecific male may be necessary for oestrus and ovulation to occur does not seem to have been suspected for macropodoids. There seems to be no doubt that females of the well-studied macropodids, e.g. Macropus rufus, $M$. eugenii and $M$. rufogriseus, ovulate spontaneously and undergo regular oestrous cycles in the absence of a male (Merchant, 1979; Merchant \& Calaby, 1981; Sharman \& Calaby, 1964). However, this may not be so for females of all potoroids. Johnson (1978) found that the potoroid Aepyprymnus rufescens has a pattern of reproduction similar to that of $B$. gaimardi and $B$. lesueur, birth occurring 18.7 days after removal of pouch young and post partum oestrus 2 days later. In contrast Moors (1975) found that females returned to oestrus 2-9 days after removal of pouch young and did not undergo 
oestrus after parturition. He also recorded oestrous cycles (based on vaginal smears) of variable length, from 28 to 36 days. These discrepancies could be explained if Johnson kept his females always with a male and if Moors had made his observations on females separated from males.

Male-induced oestrus has been reported previously for one marsupial, Monodelphis domestica, in the Didelphidae (Fadem, 1985). The oestrous cycle is approximately 32 days long in this species, yet $91.6 \%$ of conceptions occur within 13 days of pairing, and isolated females do not show a regular oestrous cycle (Fadem, 1985, 1987).

Continuously breeding macropodoid species do not become anoestrous except under extreme environmental stress. Nonmated females continue to undergo oestrous cycles and lactating females are in a state of quiescence, characterized by the presence of a partly developed corpus luteum in one ovary, uteri with well-developed but nonsecretory endometrium and a diapause embryo in one uterus. This lactational quiescence can be clearly distinguished from anoestrus, where the ovaries contain only small follicles and corpora atretica and where the uterine endometrium consists mostly of stroma with sparse small glands. The reproductive system in $B$. penicillata, which does not have oestrous cycles in the absence of a male, but which can resume cycles within 4-6 days of return to the male, remains to be investigated.

This study received financial support from the Australian Research Council. I am grateful to B. Hancl and C. Horne for their dedicated care of the bettong colony and for technical assistance. I thank L. Hinds for many valuable discussions.

\section{References}

Delroy, L.B., Earl, J., Radbone, I., Robinson, A.C. \& Hewett, M. (1986) The breeding and re-establishment of the brush-tailed bettong, Bettongia penicillata, in South Australia. Australian Wildlife Research 13, 387-396.

Fadem, B.H. (1985) Evidence for the activation of female reproduction by males in a marsupial, the gray short tailed opossum (Monodelphis domestica). Biology of Reproduction 33, 112-116.

Fadem, B.H. (1987) Activation of estrus by pheromones in a marsupial: stimulus control and endocrine factors. Biology of Reproduction 36, 328-332.

Hinds, L.A. \& Smith, M.J. (1992) Evidence from plasma progesterone concentrations for male-induced ovulation in the brush-tailed bettong, Bettongia penicillata. Journal of Reproduction and Fertility 95, 291-302.

Johnson, P.M. (1978) Studies of Macropodidae in Queensland. 9. Reproduction of the rufous ratkangaroo (Aepyprymnus rufescens (Gray)) in captivity with age estimation of pouch young. Queensland Journal of Agricultural and Animal Sciences 35, 69-72.

Merchant, J.C. (1979) The effect of pregnancy on the interval between one oestrus and the next in the tammar wallaby, Macropus eugenii. Journal of Reproduction and Fertility 56, 459-463.

Merchant, J.C. \& Calaby, J.H. (1981) Reproductive biology of the red-necked wallaby (Macropus rufogriseus banksianus) and Bennett's wallaby (M.r. rufogriseus) in captivity. Journal of Zoology 194, 203-217.

Moors, P.J. (1975) The urogenital system and notes on the reproductive biology of the female rufous rat-kangaroo, Aepyprymnus rufescens (Gray)
(Macropodidae). Australian Journal of Zoology 23, 355-361.

Parker, P. (1977) An ecological comparison of marsupial and placental patterns of reproduction. In The Biology of Marsupials, pp. 273-286. Eds B. Stonehouse \& D. Gilmore. Macmillan Press, London.

Rose, R.W.(1987) Reproductive biology of the Tasmanian bettong (Bettongia gaimardi: Macropodidae). Journal of Zoology 212, 59-67.

Sharman, G.B. \& Calaby, J.H. (1964) Reproductive behaviour in the red kangaroo, Megaleia rufa, in captivity. CSIRO Wildlife Research 9, 58-85.

Smith, M.J. (1981) Morphological observations on the diapausing blastocyst of some macropodid marsupials. Journal of Reproduction and Fertility 61, 483-486.

Smith, M.J. (1989) Release of embryonic diapause in the brush-tailed bettong Bettongia penicillata. In Kangaroos, Wallabies and Rat-Kangaroos, pp. 31732I. Eds G. Grigg, P. Jarman \& I. Hume. Surrey Beatty and Sons Pty Ltd, New South Wales, Australia.

Tyndale-Biscoe, C.H. (1968) Reproduction and postnatal development in the marsupial Bettongia lesueur (Quoy and Gaimard). Australian Journal of Zoology 16, 577-602.

Tyndale-Biscoe, C.H. (1984) Mammals-marsupials. In Marshall's Physiology of Reproduction, 4th edn (Vol. I) pp. 386-454. Ed. G. E. Lamming. Churchill Livingstone, Edinburgh.

Tyndale-Biscoe, H. \& Renfree, M. (1987) Reproductive Physiology of Marsupials. Cambridge University Press, Cambridge, UK.

Received 28 May 1991 